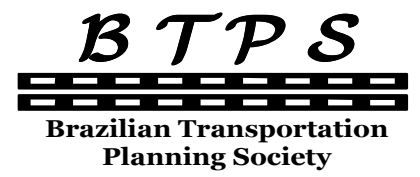

Journal of Transport Literature

Vol. 8, n. 3, pp. 290-307, Jul. 2014

Research Directory

\title{
Polo gerador de viagens: análise de um terminal urbano de passageiros anexo a um centro comercial
}

[Trip generation hub: analysis of an urban passenger terminal attached to a commercial center]

\author{
Elen de Oliveira Mendes*, José Aparecido Sorratini \\ Federal University of Uberlândia - Brazil
}

Submitted 6 May 2013; received in revised form 30 Sep 2013; accepted 1 Nov 2013

\begin{abstract}
Resumo
O estudo analisa a dinâmica de um Polo Gerador de Viagem - PGV, as viagens geradas, sua área de influência e o impacto do trânsito no seu entorno. 0 PGV estudado foi o Terminal Central de integração de ônibus urbano de Uberlândia, MG, Brasil, que possui um shopping center anexo com, aproximadamente, 80 lojas e um estacionamento coberto com 262 vagas. Estima-se que, diariamente, 144.000 pessoas frequentam o PGV. Estudou-se o referencial teórico ligado ao tema, o manual do DENATRAN para tratamento de PGV. Ainda, como parte da metodologia, foi feita uma pesquisa de campo, dentro do empreendimento e observação do comportamento de pedestres e condutores nas imediações do PGV. A pesquisa foi desenvolvida com o objetivo de serem obtidas a origem e o destino das pessoas que frequentam o empreendimento. Foram feitos levantamentos de dados de tráfego de veículos nas imediações do PGV, determinado o volume de veículos e o nível de serviço nas principais interseções. A pesquisa apresentou os impactos gerados pelo empreendimento no sistema viário, constatando-se que a maioria dos cruzamentos próximos ao local opera no Nível de Serviço F.
\end{abstract}

Palavras-Chave: polo gerador de viagem, terminal urbano de passageiros, análise de impacto do tráfego.

\begin{abstract}
This study analyzes the dynamics of a Trip Generating Developments - TGDs, the trips created, its area of influence and the impact that it has on traffic in the surrounding area. The PGV that was studied, was the Terminal Central Integration of Urban Bus in Uberlândia, MG, Brazil, which has a mall attached with approximately 80 shops and covered parking with 262 spaces. It is estimated that daily, 144,000 people are attending the TGD. Thus, were studied: the theoretical framework, on the subject, the Handbook of DENATRAN for treating TGD. Still, as part of the methodology, a research was conducted in the field, within the own enterprise, and an observing the behavior of drivers and pedestrians in the proximity of TGD. The research was developed with the goal of being get the source and the destination of people who attend the project. It was conducted, a survey data of vehicles traffic, on TGD intermediations, in order to collect the vehicles volume and level of service in major intersections. The research, presented the impacts produced by the enterprise on the road system, noting that, most near intersections where the TGD is located, operates at Level of Service F.
\end{abstract}

Key words: trip generating developments, urban passenger terminal, traffic impact analysis.

*Email: elen_morrinhos@yahoo.com.br.

\section{Recommended Citation}

Mendes, E. O. and Sorratini, J. A. (2014) Polo gerador de viagens: análise de um terminal urbano de passageiros anexo a um centro comercial. Journal of Transport Literature, vol. 8, n. 3, pp. 290-307.

- JTL/RELIT is a fully electronic, peer-reviewed, open access, international journal focused on emerging transport markets and published by BPTS - Brazilian Transport Planning Society. Website www.transport-literature.org. ISSN 2238-1031. 


\section{Introdução}

A evolução dos meios de transporte foi uma consequência do desenvolvimento das cidades. À medida que as pessoas precisam se locomover para realizar diversas atividades e, com a expansão urbana, o uso do automóvel se popularizou e aumentou Também a necessidade de se investir no transporte público. Desta forma, cresceu a premência de se planejar vias que proporcionem um deslocamento eficaz e seguro dos veículos.

Mas o planejamento viário vai além de se pensar apenas no deslocamento eficaz e seguro dos veículos. Ele deve considerar os cidadãos que circulam pela cidade à pé, de bicicleta, cadeiras de roda e também as pessoas com baixa mobilidade (idosos, gestantes, crianças entre outros).

Assim, podemos considerar que, juntamente com a ânsia do cidadão de ir e vir, o crescimento populacional no Brasil e o aumento da frota de veículos, vários transtornos foram desencadeados ligados à circulação urbana. Alguns inconvenientes que ocorrem nas vias sem planejamento são os acidentes de trânsito, os congestionamentos, a poluição atmosférica e os conflitos entre veículos e pedestres. Ou seja, nas grandes cidades um dos maiores problemas que precisa ser mais efetivamente enfrentado está ligado ao deslocamento seguro no trânsito.

A circulação viária também é afetada por empreendimentos chamados de Polos Geradores de Viagens - PGV's. Tais empreendimentos instalados em locais indevidos afetam a boa fluidez do trânsito. Por produzirem um contingente elevado de viagens, os PGV causam acidentes e prejudicam a qualidade de vida das pessoas que vivem no seu entorno (CET-SP, 1983).

Conforme Portugal e Goldner (2003), os Polos Geradores de Viagens podem ser classificados, de maneira geral, como: shopping centers, hipermercados e supermercados, hospitais, estádios, hotéis, restaurantes, igrejas, terminais urbanos de passageiros etc.

Com grande variedade de empreendimentos denominados de PGV’s há a necessidade de estabelecer métodos para se analisar os impactos que esses polos podem causar. Assim, o DENATRAN (2001), elaborou um manual de tratamento de polos geradores de viagens e destaca que a implantação e operação destes empreendimentos normalmente causam impactos na circulação viária, requerendo uma análise sistêmica e tratamento que considere os seus 
efeitos indesejáveis na mobilidade e acessibilidade de pessoas e veículos e o aumento da demanda de estacionamento em sua área de influência (DENATRAN, 2001, p. 8).

O objetivo deste trabalho consiste em estudar um Polo Gerador de Viagem - o Terminal Central de integração de passageiros do transporte coletivo de Uberlândia de modo a entender os impactos causados no trânsito em seu entorno.

Pode-se dizer que os problemas provocados pela ocupação desordenada das áreas urbanas por indústrias, comércio e residências, e a construção de empreendimentos geradores de viagens, que causam impactos na sua área de instalação e no seu entorno, levam à necessidade de se criar mecanismos que minimizem as ações impactantes e ao mesmo tempo auxiliem o planejamento para a instalação desses empreendimentos.

Os órgãos públicos devem, primeiramente, analisar a instalação dos empreendimentos, avaliando os impactos de natureza negativa, para somente após permitir sua implantação. $\mathrm{O}$ Código de Trânsito Brasileiro (Brasil, 1997) traz a necessidade de se estudar os impactos causados pelos PGV antes de sua aprovação para implantação, conforme o Artigo 93: "Nenhum projeto de edificação que possa transformar-se em polo atrativo de trânsito poderá ser aprovado sem prévia anuência do órgão ou entidade com circunscrição sobre a via e sem que do projeto conste área para estacionamento e indicação das vias de acesso adequadas".

Nas cidades de grande porte são desenvolvidas leis para instalação de PGV, destacando dentre muitas, a cidade de São Paulo - SP com um estudo realizado pela Companhia de Engenharia de Tráfego da cidade, que tem como objetivo diminuir o impacto que empreendimentos de grande porte causam sobre o tráfego das vias que lhes dão acesso (CET-SP, 1983).

Por meio de análise do referencial teórico ligado ao assunto, conhecimento do Manual do DENATRAN (DENATRAN, 2001) e da CET-SP (CET, 1983, 2000) para o tratamento de PGV, do Código de Trânsito Brasileiro - CTB (Brasil, 1997), estudo do Estatuto da Cidade e do Plano Diretor do Município que será estudado o terminal Central de Uberlândia, como um PGV. Além da bibliografia nacional, utilizar-se-á o manual norte-americano de geração de viagens (ITE, 2006), para se fazer comparação entre as taxas de geração nacionais e estrangeiras. 
As etapas da metodologia desenvolvidas neste trabalho: análise do referencial teórico sobre PGVs, incluindo o conhecimento do Manual do DENATRAN (DENATRAN, 2001) e da CET-SP (CET, 1983) para o tratamento de PGV, do Código de Trânsito Brasileiro - CTB, estudo do Estatuto da Cidade e do Plano Diretor do Município que será estudado o terminal Central de Uberlândia, como um PGV. Levantamento de dados ligados ao PGV, quantidade de pessoas que frequentam o polo diariamente, a área do empreendimento, as sinalizações de trânsito presentes no entorno do polo, e ainda sua área de influência, desenvolvendo questionários para a pesquisa/entrevista de origem e destino - O/D com usuários do terminal e do Pratic Shopping. De acordo com Gil (1987) entrevista é a técnica em que o investigador se apresenta frente ao investigado e lhe faz pergunta, com o objetivo de obtenção dos dados que interessam à investigação. Uma das partes busca coletar os dados e a outra é a fonte de informação.

A pesquisa de origem e destino foi estabelecida para determinar a área de influência do polo.Foram feitas 3.000 pesquisas com as pessoas que frequentam o Terminal Central e o Pratic Shopping, na cidade de Uberlândia - MG. De acordo com o Urban Land Institute (1971) apud Portugual e Goldner (2003), o termo “área de influência” ou "área de mercado" é normalmente definido como a área em que se obtém a maior proporção de clientela contínua necessária para manutenção constante do shopping center.

Para o desenvolvimento do estudo, estruturaram-se também planilhas para uma contagem volumétrica nas principais vias de acesso ao terminal, e posteriormente fez-se o trabalho de campo para verificar a quantidade de veículos que transitam no entorno imediato do polo. E assim, avaliar o nível de serviço dos controladores de tráfego das interseções próximas ao PGV utilizando-se de programas computacionais. Para a etapa de estudo em questão utilizouse o programa Highway Capacity Software - HCS.

E ainda analisaram-se os impactos gerados pela circulação de trânsito próximo ao polo, sendo o foco principal os acidentes de trânsito. E para enriquecer mais o estudo, a Seção 1 vem expondo uma breve explicação sobre os polos geradores de viagem. 


\section{Polos geradores de viagens - definições e classificações}

Com o processo de desenvolvimento tecnológico, as construções grandiosas crescem cada vez mais e empreendimentos gigantescos se espalham pelas cidades. Alguns autores que estudam o tema Polos Geradores de Viagens, afirmam que estes empreendimentos afetam a estrutura e circulação urbana, pois atraem vários serviços e pessoas, e geram efeitos negativos na circulação de pessoas e veículos.

A Associação Nacional de Transportes Públicos - ANTP (2009) aponta que os empreendimentos denominados PGVs são estruturações urbanas que atraem grande número de deslocamento, ocasionando reflexos negativos na circulação viária em seu entorno e, ainda podendo causar prejuízo à acessibilidade da região e acentuar as condições de conforto e segurança dos condutores e pedestres.

A Companhia de Engenharia de Tráfego de São Paulo - CET-SP caracteriza os polos geradores de viagem como empreendimentos capazes de promover um incremento no número de viagens com possibilidade de atrair e produzir viagens causando impactos relativos à segurança de veículos e pedestres e na circulação viária interna e externamente à área de implantação dos mesmos.

Para Goldner (1994), os PGV's são aqueles empreendimentos que, mediante a oferta de bens e serviços, geram e atraem um grande número de viagens e, consequentemente, causam reflexos na circulação de tráfego do entorno, tanto em termos de acessibilidade e fluidez do tráfego, muitas vezes com repercussões em toda uma região, quanto em termos da segurança de veículos e pedestres.

A Rede Ibero-Americana de Estudos de Polos Geradores de Viagens (2012) explicita que os PGVs apresenta o desenvolvimento de atividades que tem o potencial de exercer grande atratividade sobre a população, e assim produzir uma quantidade considerada de viagem. E ainda, necessitar de espaços para estacionamento, carga e descarga, embarque e desembarque, potencializando impactos. E destaca alguns tipos de PGVs: sopping centers, hipermercados, hospitais, universidades, estádios, estações de transporte público. 
A classificação dos PGV’s se apresenta incerta. De acordo com a Constituição da República Federativa do Brasil (Brasil, 1988), compete aos municípios a promoção do adequado ordenamento territorial, mediante planejamento e controle do uso e ocupação do solo (Artigo 30). O Código de Trânsito Brasileiro (Brasil, 1997) estabelece que nenhum projeto de edificação que venha a ser um polo atrativo de trânsito poderá ser aprovado sem a prévia autorização do órgão ou entidade com circunscrição sobre a via (Artigo 93). Dessa forma, infere-se que compete ao poder municipal classificar os empreendimentos em polos geradores de viagens e estabelecer critérios adequados para tal definição. Geralmente se observa apenas a área construída do empreendimento e a quantidade de vagas de estacionamento e de carga e descarga.

A CET-SP (1983) classifica os empreendimentos geradores de viagens em:

- micropolos, cujos impactos isolados são pequenos, mas quando agrupados podem gerar impactos significativos, como farmácias, escolas, restaurantes, bares etc.;

- grandes polos (ou macropolos), abrangem as construções de grande porte que, mesmo isoladamente, podem causar impactos significativos, como hospitais, universidades, shopping centers, hotéis etc.

Silveira (1991) ressalta que o polo gerador de viagem traduz o encadeamento de três fatores: desenvolvimento de atividades, geração de viagens e geração de tráfego, ao concentrar num único local atividades específicas que produzem e atraem grande quantidade de viagens e, conseqüentemente, de tráfego.

Após conceitos e classificações de PGV, a Seção 2 apresenta o estudo de um empreendimento considerado um polo de importância econômica e espacial.

\section{Caracterização do contexto em estudo}

O município de Uberlândia foi fundado em 1822 e é considerado um importante entreposto comercial em razão da sua localização privilegiada, constituindo-se em um importante entroncamento rodoferroviário, que facilita a ligação com os principais centros urbanos do país. 
Uberlândia localiza-se no sudoeste do estado de Minas Gerais, na Região do Triângulo Mineiro, conforme mostra a Figura 1. Constitui-se em uma cidade de porte médio (IBGE, 2009).

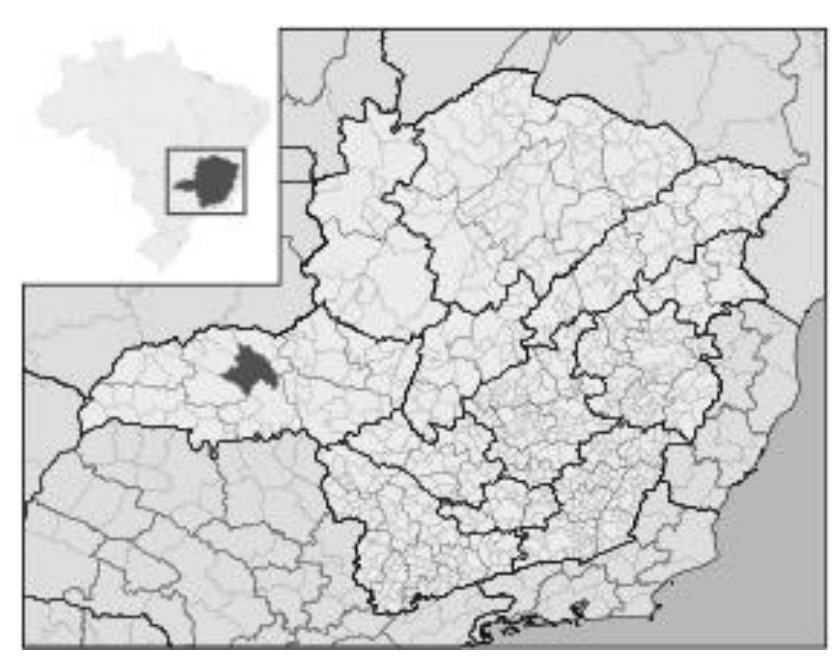

Figura 1- Mapa do Estado de Minas Gerais em destaque o município de Uberlândia

A partir de 1950, a cidade de Uberlândia passou por um acelerado processo de urbanização, seguido por um aumento na frota automotiva que chega a 311.127 veículos (Detran/MG Departamento Estadual de Trânsito, dezembro de 2010). Esse processo, aliado a uma ocupação desordenada do solo, resultou em uma ineficiência no desenvolvimento do sistema viário e no atendimento da demanda por transporte público por ônibus.

O município não tinha um planejamento urbano adequado para receber a população que chegava e assim os conflitos foram surgindo, em especial os ligados ao trânsito.

Uberlândia vivenciou um processo de desenvolvimento econômico, o qual atraiu diferentes empreendimentos classificados como PGV's, como: hospitais, shoppings, universidades, indústrias, terminais de ônibus, teatros, escolas etc. Estes polos causam e atraem a circulação de pessoas, gerando impactos urbanos.

A cidade de Uberlândia está dividida em cinco setores, e é no setor central onde se localiza um dos terminais urbanos de passageiros denominado de Terminal Central, que é o objeto de estudo deste trabalho. O Terminal Central faz parte de Sistema Integrado de Transporte - SIT, proposto no Plano Diretor de 1992. Sua implantação, porém, ocorreu somente no dia 05 de 
Julho de 1997. O sistema conta ainda com mais quatro terminais urbanos de passageiros, como apresentado na Figura 2.

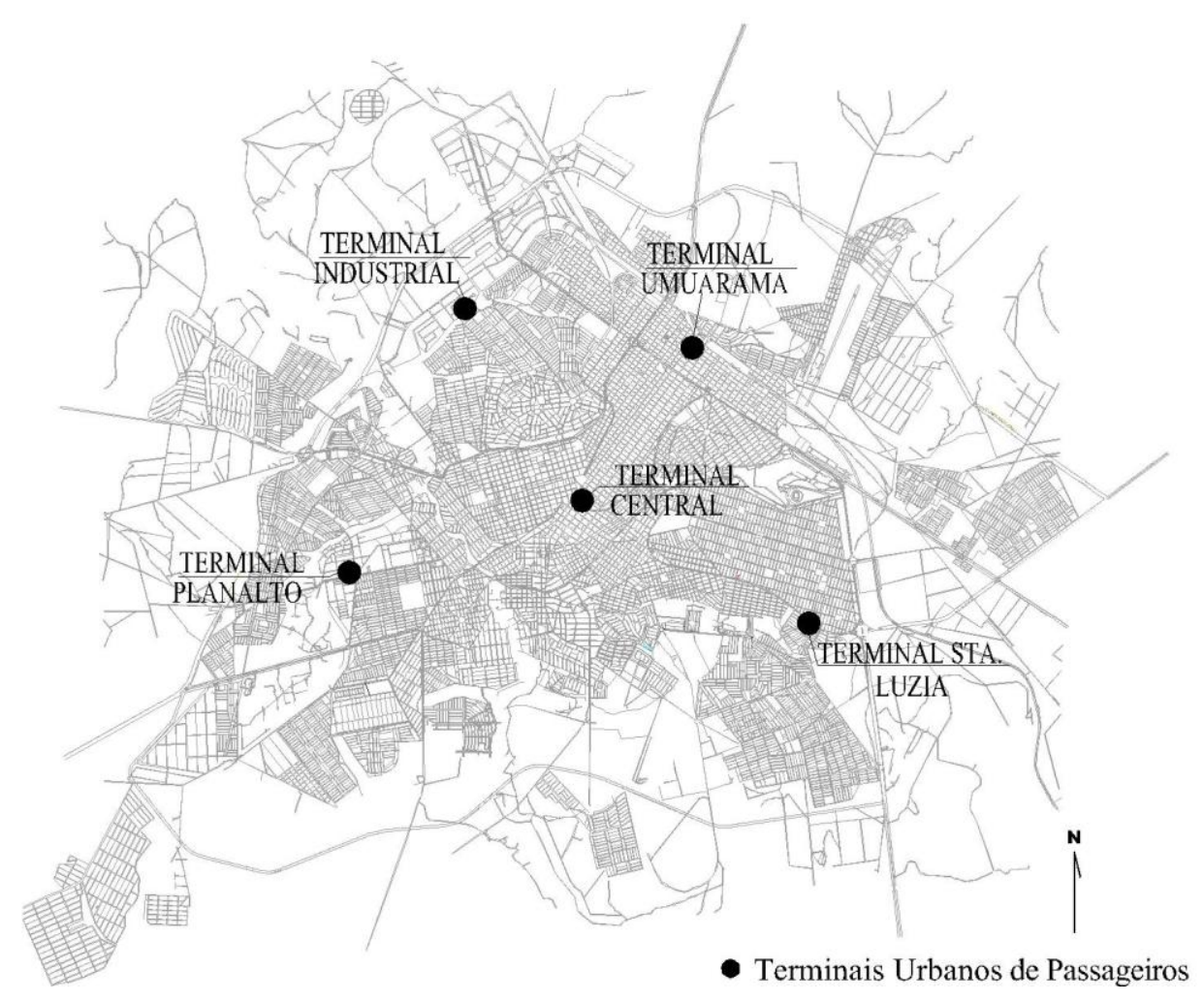

Figura 2 - Planta dos cinco terminais do SIT - 2010

O Terminal Central consiste em um complexo constituído de áreas e edificações destinadas a embarque e desembarque de passageiros e ainda conta com um complexo comercial que iniciou com 62 lojas, e no ano de 2010, conta com mais de 80 lojas e agências bancárias, denominado Pratic Shopping. Possui uma área de $15.746 \mathrm{~m}^{2} \mathrm{e}$ área coberta de $9.371 \mathrm{~m}^{2}$.

A Companhia Administrativa de Terminais Urbanos e Centros Comerciais - Comtec, constituída no ano de 1995, é responsável pela gestão do Pratic Shopping, e também opera e administra os cinco terminais urbanos.

O Terminal Central de passageiros e o Pratic Shopping estão localizados entre as principais vias do setor central de Uberlândia e, ainda, próximo ao Terminal Central existe outro polo gerador de viagens, o Fórum da cidade. Estes fatores nos fazem entender a existência de um 
fluxo intenso de veículos no entorno do empreendimento em estudo. Além desse grande fluxo de veículos o PGV atrai aproximadamente 144.000 pessoas por dia.

Por ser um terminal de passageiros e possuir uma estrutura comercial favorável o Terminal Central atrai e gera viagens em seu entorno, sendo caracterizado como Polo Gerador de Viagens. Em seu entorno foram implantados estacionamentos, áreas de carga e descarga, áreas de embarque e desembarque, sinalização adequada das vias mais próximas, faixa de pedestre que, desta forma, geram um grande volume de tráfego de veículos e pessoas. A implantação do PGV causou vários impactos indesejáveis em seu entorno, por isso a necessidade de se estudá-lo.

\subsection{Coleta de dados}

Para se realizar a coleta de dados, foi feita uma busca nas bases teóricas e referências bibliográficas como meio de direcionar o trabalho. Foram realizadas pesquisas e consultas em instituições públicas - Prefeitura Municipal de Uberlândia e Universidade Federal de Uberlândia - e empresas privadas - COMTEC para assim estruturar a base de dados.

De posse da quantidade de pessoas que frequentam o Terminal Central de Passageiros e o Pratic Shopping, 100.000 pessoa por dia e 44.000 pessoas por dia, respectivamente, estimouse o número de pessoas que seriam entrevistadas na pesquisa de “Origem e Destino - OD”.

Conforme Levin (1987), para que uma pesquisa por amostragem seja apresentada com dados referentes à realidade, devem ser entrevistadas pelo menos $2 \%$ da quantidade total da amostra que são 144.000 pessoas que frequentam o Terminal Central e o Pratic Shopping. Seguindo tal critério, 3.000 entrevistas foram realizadas. Assim, das 3.000 entrevistas, 2.261 foram feitas nas plataformas de embarque e desembarque de passageiros do Terminal Central e 739 das entrevistas foram feitas com os frequentadores do Pratic Shopping.

As pesquisas foram realizadas entre os dias 11 e 14 de maio e 18 e 21 de maio de 2010, totalizando 8 dias de pesquisa. E também foram realizadas em todos os períodos do dia, manhã, tarde, noite, por oito pesquisadores. O horário que se desenvolveu a pesquisa foi das 7:00hs às 20:00hs. A pesquisa foi feita com pessoas maiores de 18 anos, que frequentaram as plataformas de embarque e desembarque do Terminal Central, o Pratic Shopping. 
A pesquisa foi feita com o objetivo de conhecer a origem e o destino das pessoas que utilizam o Terminal Central e o Pratic Shopping. Faz-se necessário conhecer o bairro de onde a pessoa entrevistada vem e para qual bairro ou setor ela se destina, para assim, determinar a área de influência do Terminal Urbano de Passageiros.

$\mathrm{Na}$ entrevista foi questionado, também, qual modo de transporte foi utilizado para se chegar ao PGV, por qual entrada ou acesso chegou-se ao empreendimento, por quanto tempo as pessoas permaneceram no Terminal ou no Pratic Shopping e por qual motivo se dirigiu ao local objeto da pesquisa.

\subsection{Definição da área de influência do Polo}

Para se definir a área de influência do Terminal Central, a pesquisa de campo procurou saber de qual local as pessoas saíam para iniciar a viagem (através da pergunta "Em qual bairro você mora?") e para qual local ela estava se deslocando (através da pergunta "Para qual bairro você irá?").

No município de Uberlândia estão cadastrados 64 bairros integrados, segundo a Secretaria Municipal de Planejamento Urbano, e 4 distritos (Tapuirama, Cruzeiro dos Peixotos, Martinésia e Miraporanga).

De acordo com os dados da pesquisa, o bairro que mais atrai (origina) pessoas para o Terminal Central e o Pratic Shopping é o Bairro Centro, com 479 pessoas. A Figura 3 apresenta os 10 bairros com maior número de pessoas que se dirigem ao PGV, de acordo com a pesquisa.

Da mesma forma, o bairro que mais atrai pessoas, quando saem do PGV, é o Bairro Centro, com 425 entrevistados. A Figura 4 apresenta os 10 bairros com maior número de pessoas que saem do PGV, de acordo com a pesquisa. 


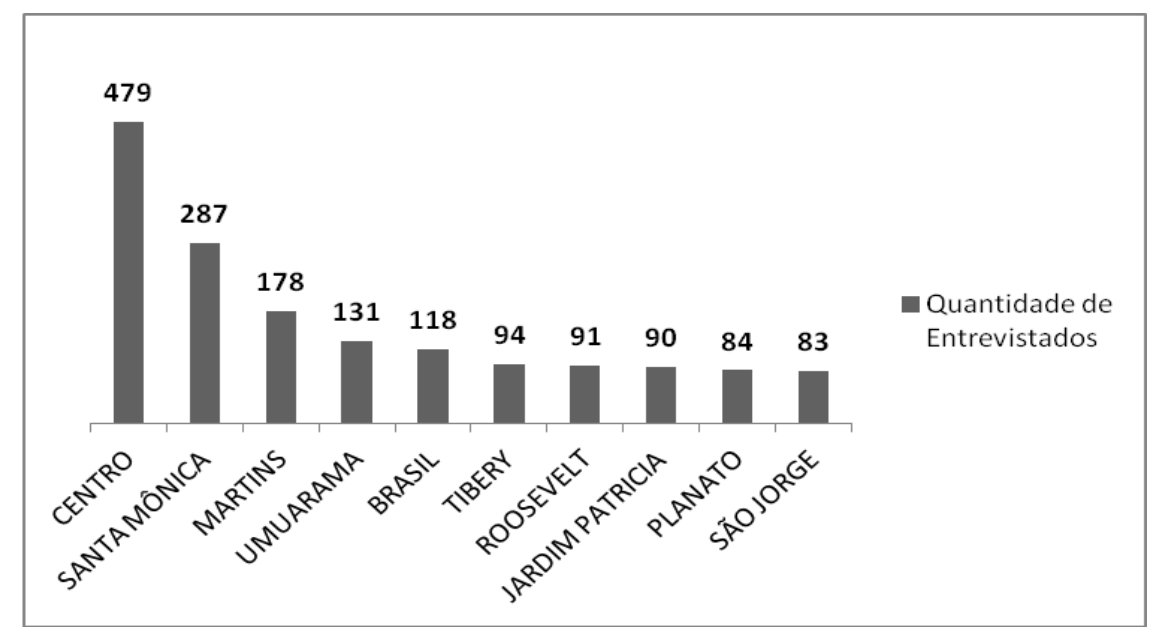

Figura 3 - 10 Bairros com maior número de origem dos entrevistados

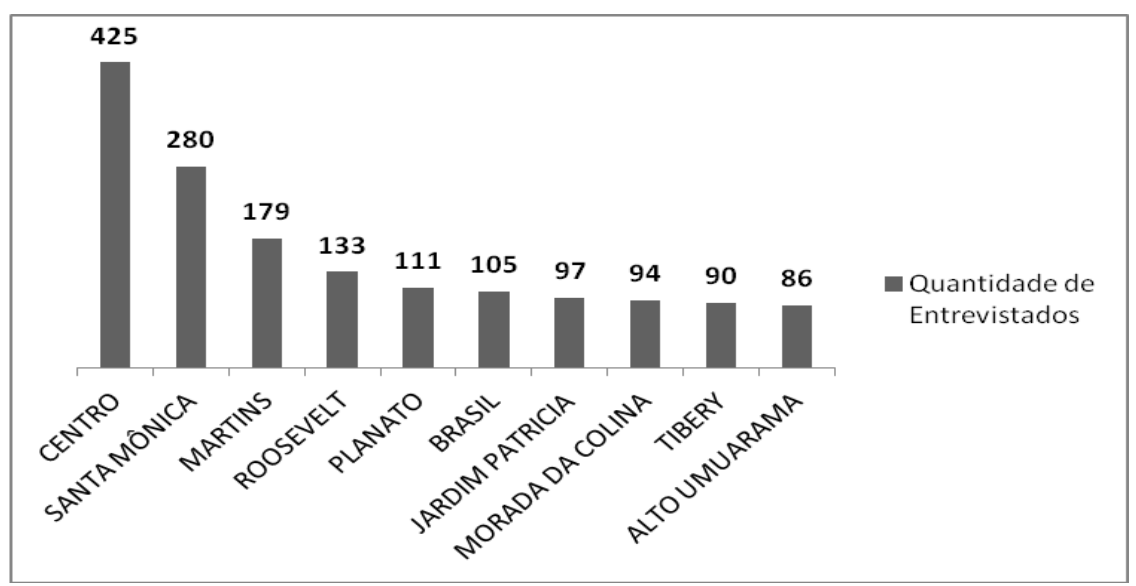

Figura 4 - 10 Bairros com maior número de destino dos entrevistados

Outra conclusão, a que nos leva a pesquisa, é que $57 \%$ dos entrevistados frequentam o PGV somente para utilizar o transporte público, como demonstra a Figura 5.

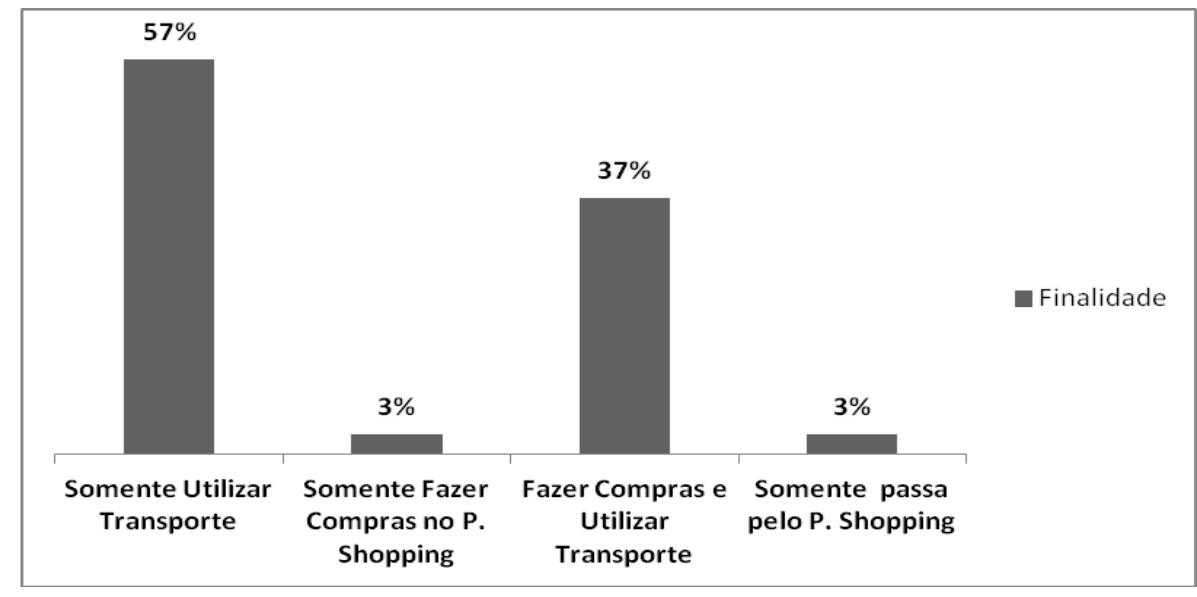

Figura 5 - Finalidade de viagem dos entrevistados ao PGV 
Quanto à faixa etária dos entrevistados, a pesquisa mostra que a maioria dos usuários se encontra na faixa etária entre 18 e 30 anos, conforme Figura 6. A maioria dos entrevistados é do gênero feminino, como se observa na Figura 7.

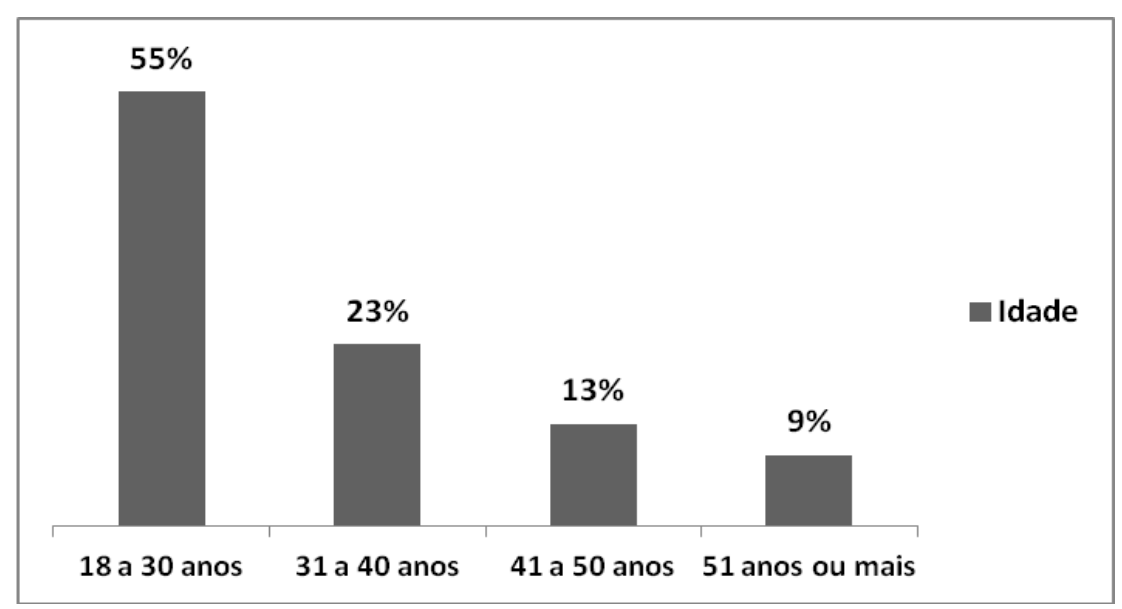

Figura 6 - Faixa etária dos entrevistados

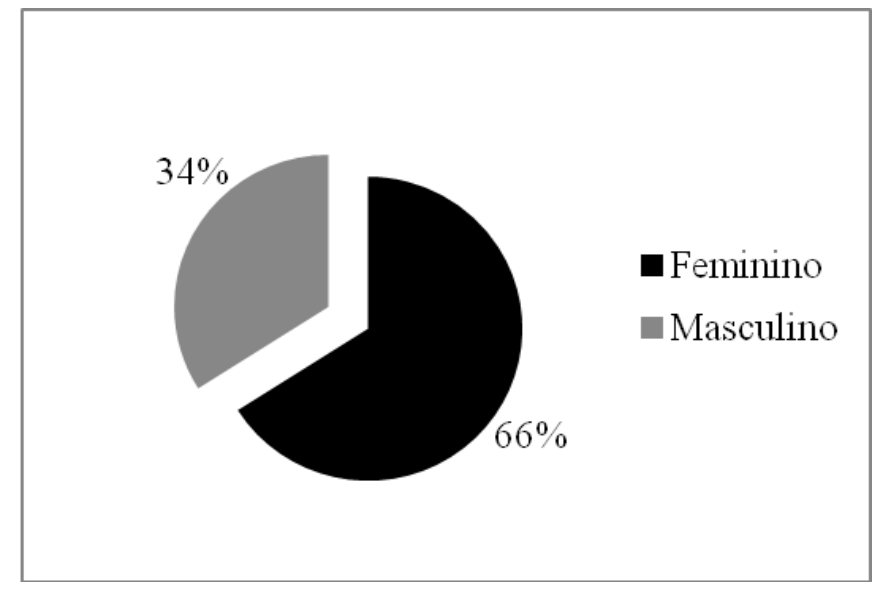

Figura 7 - Gênero dos entrevistados 


\subsection{Impactos do PGV}

Nas últimas décadas houve um crescimento significativo da ocupação periférica das cidades e da taxa de motorização. Os impactos advindos desse crescimento podem comprometer a qualidade de vida da população, a circulação viária, o uso e ocupação do solo, entre outros.

Segundo Silveira (1991), um empreendimento considerado PGV provoca possíveis alterações na estrutura urbana afetando a acessibilidade da área, o valor dos imóveis e terrenos, a localização do comércio e o uso e ocupação do solo.

O fluxo de veículos no entorno do Terminal Central é controlado por meio de semáforos. Desde a implantação do Pratic Shopping e do Terminal Central, em 1997, inúmeras foram as mudanças ocorridas nas vias de acesso ao empreendimento e várias faixas de pedestres foram instaladas a fim de aumentar a segurança e evitar acidentes.

Entretanto, a quantidade de veículos faz com que a sua circulação e a de pedestres seja dificultada, gerando conflitos, congestionamentos e atrasos. A Tabela 1 mostra a quantidade diária de veículos no entorno do Terminal Central durante os dias 12 e 18 de abril de 2010. De acordo com os dados o dia de maior fluxo foi a segunda-feira, com 171.881 mil veículos nos cruzamentos.

Tabela 1- Volume veicular - cruzamentos em torno do Terminal Central

\begin{tabular}{|c|c|c|c|c|c|c|c|}
\hline \multirow[t]{2}{*}{ Cruzamento } & \multicolumn{7}{|c|}{ Número de veículos durante a semana } \\
\hline & Seg & Ter & Qua & Qui & Sex & Sáb & Dom \\
\hline $\begin{array}{l}\text { Av. João Pinheiro x Av. João } \\
\text { Pessoa x Av. João Pinheiro }\end{array}$ & 52.588 & 48.119 & 48.600 & 49.467 & 48.647 & 33.252 & 28.868 \\
\hline $\begin{array}{l}\text { Av. João Pessoa x Av. Afonso } \\
\text { Pena x Av. João Pessoa }\end{array}$ & 50.186 & 48.821 & 45.257 & 46.164 & 44.735 & 31.681 & 18.048 \\
\hline $\begin{array}{l}\text { Av. João Pinheiro x Av. Salvador } \\
\text { A. Tangari }\end{array}$ & 39.138 & 38.112 & 37.498 & 37.967 & 40.092 & 33.870 & 23.486 \\
\hline $\begin{array}{l}\text { Av. Salvador A. Tangari x Av. } \\
\text { João Pinheiro x Bairro }\end{array}$ & 18.932 & 18.448 & 18.373 & 18.392 & 19.635 & 14.759 & 10.457 \\
\hline $\begin{array}{l}\text { Av. Salvador A. Tangari x Av. } \\
\text { João Pinheiro x Centro }\end{array}$ & 11 & 10 & 10.367 & 10.286 & 154 & 9.407 & 5.959 \\
\hline Total de veículos & 171.881 & 163.902 & 160.095 & 162.276 & 164.263 & 122.969 & 86.818 \\
\hline
\end{tabular}


Os acessos de entrada de pedestres e veículos do Pratic Shopping são três para pedestres e um acesso para veículos particulares, conforme a Figura 8. Na pesquisa observou-se que das 739 pessoas entrevistadas, que acessam o Pratic Shopping, $70 \%$ entram pelo acesso das plataformas de ônibus, $15 \%$ pelo acesso da Av. João Pessoa, 10\% pela entrada da Av. Salvador Américo Tangari e 5\% pelo acesso da Av. Salvador Américo Tangari sobre o viaduto.

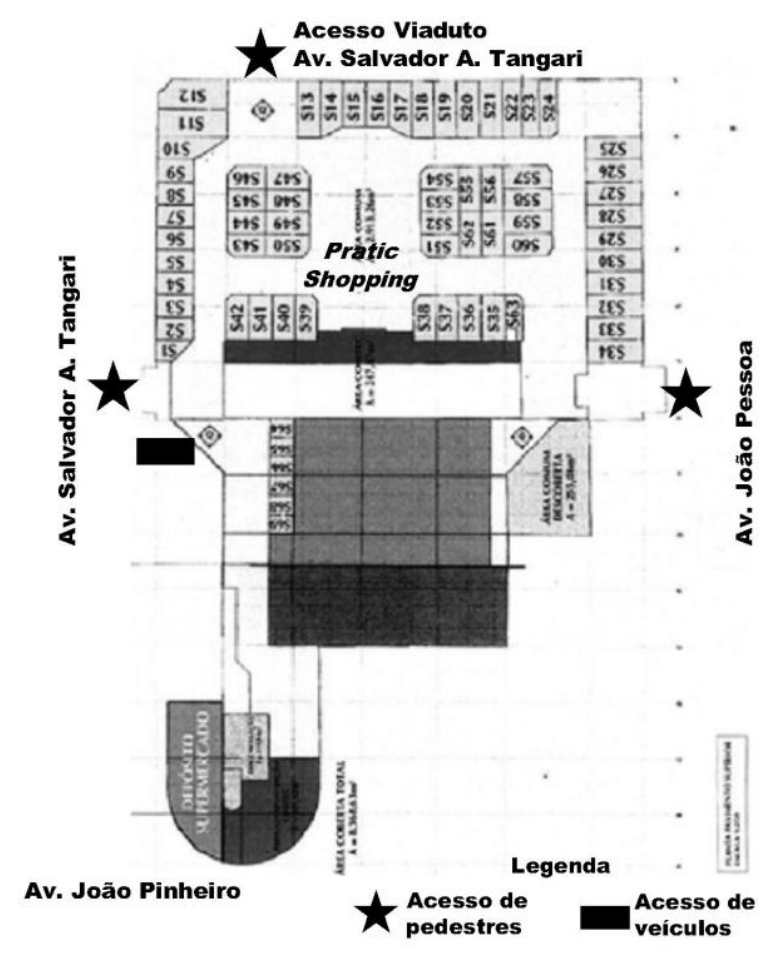

Figura 8 - Acessos ao Pratic Shopping

As plataformas de embarque e desembarque do Terminal Central possuem dois acessos distintos para ônibus, conforme a Figura 9, e um acesso para pedestres pelo Pratic Shopping. Como observado na pesquisa, 2261 pessoas chegam ao PGV pelas plataformas do Terminal Central, sendo que do total de entrevistados 55\% acessam as Plataformas do Terminal Central pela Av. João Pinheiro, 37\% pela Av. Afonso Pena e 8\% pelas catracas do Pratic Shopping. 


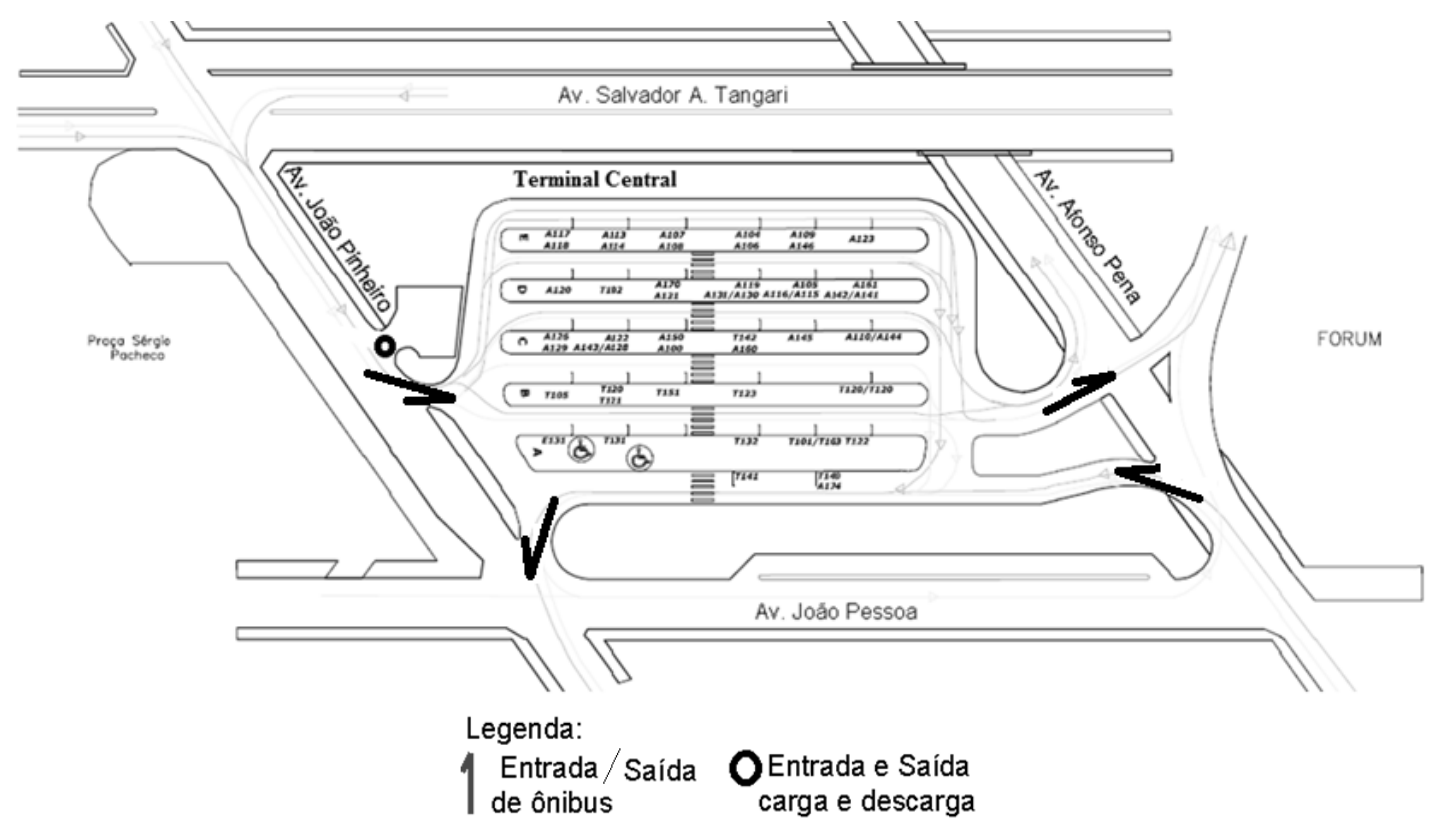

Figura 9 - Acessos ao Terminal Central

Pode-se afirmar que o trânsito é dinâmico em toda uma cidade, porém próximo a empreendimentos de grande porte ele é encarado com sendo mais complexo, tornando-se uma questão técnica, social e política. Geralmente, o planejamento urbano não observa essas questões e faz com que o trânsito fique conflituoso. Segundo Vasconcelos (1992), o trânsito é o conjunto de todos os deslocamentos diários, feitos pelas calçadas e vias da cidade, e que aparece na rua na forma da movimentação geral de pedestres e veículos.

A situação da circulação urbana em Uberlândia já é preocupante, e os acidentes de trânsito estão aumentando como o passar dos anos. A tabela 2 evidencia essa realidade.

Tabela 2 - Uberlândia - MG: acidente de trânsito por ano em vias 2001 a 2009

\begin{tabular}{c|c}
\hline Ano & Total \\
\hline $\mathbf{2 0 0 1}$ & 6.879 \\
\hline $\mathbf{2 0 0 2}$ & 7.499 \\
\hline $\mathbf{2 0 0 3}$ & 7.972 \\
\hline $\mathbf{2 0 0 4}$ & 7.741 \\
\hline $\mathbf{2 0 0 5}$ & 9.080 \\
\hline $\mathbf{2 0 0 6}$ & 2.267 \\
\hline $\mathbf{2 0 0 7}$ & 10.133 \\
\hline $\mathbf{2 0 0 8}$ & 10.923 \\
\hline $\mathbf{2 0 0 9}$ & 11.591 \\
\hline
\end{tabular}

Fonte: Settran-Controle de Tráfego em Área (CTA) estatística-2009 
E ao observar os dados de acidentes fez se necessário avaliar o volume de veículos no entorno do PGV. Desta forma fez-se uma análise do nível de serviço dos cruzamentos no entorno do polo. A análise teve como objetivo apontar os impactos negativos gerados pelo elevado número de veículos que trafegam nas mediações do empreendimento, que resultam em congestionamentos, atrasos e afetam, assim, a capacidade e o nível de serviço das vias. O nível de serviço nas vias é determinado, principalmente, pela quantidade de veículos que circulam nas mesmas. A determinação do nível de serviço foi feita por meio do programa Highway Capacity Software - HCS, do Hichway Capacity Manual - HCM, manual de capacidade dos Estados Unidos. O programa avalia os níveis de serviços individuais das aproximações de uma interseção assim como o nível de serviço geral da mesma.

O HSC estabelece seis níveis de serviço, de "A" até " $F$ ", sendo o nível de serviço " $A$ " o melhor nível para o cruzamento e o nível de serviço "F" o pior. Assim, quando o nível de serviço está ruim devem ser tomadas medidas físicas ou operacionais para melhorar o desempenho do tráfego na interseção. Após a coleta de dados dos cruzamentos foi necessário introduzir no programa HCS as demandas de veículos das vias estudadas para se avaliar o cruzamento. Além dos dados de demanda de veículos foi necessário definir o sentido das vias, o número de faixas, as possíveis conversões, os tempos de semáforos e demais dados físicos e de característica do tráfego exigidos pelo programa.

No programa HCS foram estudados os três cruzamentos existentes no entorno do Terminal Central: Av. Salvador Américo Tangari com Av. João Pinheiro, Av. João Pinheiro com Av. João Pessoa e Av. João Pessoa com Av. Afonso Pena. Os relatórios dos cruzamentos gerados pelo programa indicam que os mesmos, de uma maneira geral, operam no nível de serviço "F”, ou seja, o pior nível. Ao se observar as aproximações, somente no cruzamento da Av. João Pinheiro com a Av. João Pessoa, especificamente a conversão à esquerda na Av. João Pinheiro, opera no nível de serviço "B”.

Observa-se que no local há, principalmente, a formação de filas e atrasos, que comprometem o desempenho do tráfego e da segurança no local, principalmente devido à grande quantidade de conflitos existentes entre veículos e pedestres. Desta forma, o PGV traz transtornos ao trânsito no local e requer dos técnicos de trânsito municipal um estudo mais apurado que vise melhorar o nível de serviço na região. 


\section{Conclusão}

Este trabalho mostrou a dinâmica de um Polo Gerador de Viagens, composto por um terminal urbano de ônibus e um centro comercial - Pratic Shopping. Foi apresentada uma análise da pesquisa realizada nesses empreendimentos e dos impactos causados na área do entorno.

Foi possível notar que a infraestrutura urbana existente não é suficiente para suportar o elevado número de veículos, o que afeta a circulação, acentuando os conflitos e causando acidentes.

Segundo o Ministério da Saúde (Brasil, 2008), o acidente de trânsito é um dos principais causadores de morte no Brasil. E o problema é agravado, já que a má qualidade e a falta do transporte público obriga grande parte da população a utilizar o automóvel para os seus deslocamentos diários.

Em Uberlândia, os problemas relacionados a acidentes de trânsito não são menores e a fiscalização e o planejamento do trânsito não são eficazes o suficiente para evitar as desordens. A imprudência dos motoristas ocorre por toda cidade e no entorno do Terminal Central não é diferente.

Durante observações visuais na área próxima ao empreendimento foram flagradas algumas situações de desrespeito ao Código Brasileiro de Trânsito, como as citadas abaixo:

- desrespeito ao semáforo, com veículos que avançam o sinal vermelho;

- desrespeito ao semáforo para pedestre, com pedestres que atravessam a faixa enquanto o sinal está vermelho;

- pedestres que cruzam a via, fora da faixa para pedestres;

- veículos e motos que estacionam em locais proibidos.

Uma análise detalhada deve ser realizada para verificar o impacto do tráfego de veículos e pedestres no entorno do empreendimento.

A ausência de uma legislação, de competência local, que obrigue à Avaliação de Impactos Ambientais, antes da implantação de empreendimentos de médio e grande porte também contribui para agravar os problemas no trânsito. 
Podemos concluir, pois, que esse estudo serve de suporte para os planejadores urbanos do município, de modo a orientá-los sobre como minimizar os transtornos ocasionados pelo PGV em questão.

\section{Referências}

Brasil (1988) Constituição da República Federativa do Brasil. Texto constitucional promulgado em 5 de outubro de 1998.

Brasil (1997) Código de Trânsito Brasileiro: instituído pela Lei $n^{\circ}$. 9.503, de 23-09-97. Brasília: DENATRAN.

Brasil (2008) Ministério da Saúde. Departamento de Informática do SUS. Indicadores de Dados Básicos. Rede Interagencial de informações para saúde (RIPSA). Disponível em www.tabnet.datasus.gov.br

Companhia Administrativa de Terminais Urbanos e Centros Comerciais - COMTEC (2007) Pesquisa Comtec 2007. Disponível em www.praticshopping.com.br.

Companhia de Engenharia de Tráfego - CET-SP (1983). Polos geradores de tráfego. Boletim Técnico 32, São Paulo.

Departamento Nacional de Trânsito - DENATRAN (2001). Manual de procedimentos para o tratamento de polos geradores de tráfego. Brasília: DENATRAN/FGV.

Departamento Estadual de Trânsito de Minas Gerais - DETRAN-MG (2008). Departamento Estadual de Trânsito de Minas Gerais. Disponível em www.denatran.gov.br.

Gil, A. C. (1987) Métodos e técnicas de pesquisa social. São Paulo: Atlhas.

Goldner, L. G. (1994) Uma metodologia de avaliação de impactos de shopping centers sobre o sistema viário urbano. Tese (Doutorado em Engenharia Civil), Universidade Federal do Rio de Janeiro, PET/COPPE/UFRJ, Rio de Janeiro.

Instituto Brasileiro de Geografia e Estatística - IBGE. Cidades. Disponível em www.ibge.gov.br.

Levin, J. (1987) Estatística Aplicada a Ciências Humanas. 2a. Ed. São Paulo: Editora Harbra Ltda.

Portugal, L. da S. e Goldner, L. G. (2003) Estudo de polos geradores de tráfego e de seus impactos nos sistemas viários e de transportes. São Paulo: Edgard Blücher, $1^{\text {a }}$ ed.

Rede Ibero-americana de estudo em polos geradores de viagens - RedPGV. Disponível em www.redpgv.coppe.ufrj.

Secretaria Municipal de Trânsito e Transportes - SETTRAN. Controle de Tráfego em Área - CTA. Dados de acidentes 2001 a 2009.

Secretaria Municipal de Trânsito e Transportes - SETTRAN (2007). Terminais de integração e estações.

Silveira, I. T. (1991) Análise de polos geradores de tráfego segundo sua classificação, área de influência e padrões de viagem. Dissertação (Mestrado em Engenharia Civil), Universidade Federal do Rio de Janeiro - COPPE/UFRJ, Rio de Janeiro.

Vasconcelos, E. A. (1992) O que é trânsito. $2^{\mathrm{a}}$ ed., São Paulo, Ed. Brasiliense. 